\title{
Clinical significance of video-urodynamic in female recurrent urinary tract infections
}

\author{
This article was published in the following Dove Press journal: \\ International Journal of Women's Health \\ 19 January 2016 \\ Number of times this article has been viewed
}

\section{Sameh Hijazi \\ Conrad Leitsmann}

Department of Urology, University Medical Center Goettingen, Goettingen, Germany
Correspondence: Sameh Hijazi

Department of Urology, University

Medical Center Goettingen,

Robert-Koch-Straße 40, 37075

Goettingen, Germany

Tel +4955I 392264 I

Fax +49 55I 3922213

Emailsameh_hijasi@yahoo.de
Purpose: We aimed to assess the value of video-urodynamic study (VUD) in the identification of lower urinary tract voiding dysfunction in female recurrent urinary tract infections (UTIs).

Patients and methods: A total of 54 women with recurrent UTIs who underwent VUDs between 2013 and 2015 were analyzed. They were carefully evaluated by complete history, voiding diary, physical investigation, urosonography, and VUDs.

Results: Neurogenic and non-neurogenic voiding dysfunctions were found in $4 \%$ and $63 \%$ of women respectively. Detrusor sphincter dyssynergia, detrusor underactivity, and a combination of both were found in 17\% (nine of 54), 22\% (12 of 54), and 11\% (six of 54) of women, respectively. Overactive bladder syndrome was determined in $28 \%$ (15 of 54) of women. Reduction in the maximal urinary flow rate to less than $15 \mathrm{~mL} / \mathrm{s}$ and post-void residual volume were revealed in $63 \%$ (34 of 54) and 54\% (29 of 54) of women, respectively. Stress urinary incontinence was noticed in 39\% (21 of 54) of women with a median pad usage of three pads (range: 1-15) daily. Urgency and nocturia were complaints in 54\% (29 of 54) and 43\% (23 of 54) of women, respectively. The median voiding frequency and nocturia episodes were $7 \pm 4(1-13)$ and $1 \pm 3(0-12)$, respectively.

Conclusion: Dysfunctional voiding can encourage the formation of recurrent UTIs in the female. The VUDs are the investigation of choice to diagnose voiding dysfunction.

Keywords: urodynamic study, recurrent urinary tract infection, voiding dysfunction

\section{Introduction}

Recurrent urinary tract infections (UTIs) are one of the most common nosocomial acquired bacterial infections among adult women of all ages. Several studies have shown that at least $50 \%$ of women will experience at least one UTI episode in their lifetime. $^{1-4}$

The etiology of UTIs is not definitively cleared. Several pathogen-related factors and behavioral risk factors can encourage the recurrence of UTIs in women. ${ }^{4}$ Earlier groups have shown that besides anatomical conditions of the urinary tract, urodynamic disorders are characteristic for recurrent UTIs. ${ }^{1-3,5}$ A further group reported a prevalence of voiding dysfunction in women of $2 \%-25 \% .{ }^{6}$ The voiding dysfunction can lead to recurrent UTIs in up to $42 \%$ of patients. ${ }^{1-3}$

A video-urodynamic study (VUD) is the investigation of choice to identify lower urinary tract dysfunctions by evaluating the storage and emptying function of the bladder and showing the interaction between the external urethral sphincter and detrusor muscle. Carlson et al found detrusor instability in $42 \%$ of the patients suffering from recurrent UTIs. ${ }^{5}$ Aliaev et al determined detrusor underactivity (DU) and overactive bladder $(\mathrm{OAB})$ in $39 \%$ and $42 \%$, respectively, of patients with recurrent UTIs. ${ }^{7}$

We hypothesized that dysfunctional voiding can lead to recurring UTIs in the female. Our aim was to evaluate the clinical significance of VUD and the incidence of voiding dysfunctions in the women suffering from recurring UTIs. 


\section{Patients and methods}

We analyzed the urodynamic findings in 54 women with recurrent UTIs between July 2013 and February 2015, retrospectively.

The diagnosis of recurrent UTIs was made using the standards recommended by the European Association of Urology (EAU) Guidelines on Urological Infections. ${ }^{8}$ We included women with at least three episodes of UTIs documented by urine culture during the preceding 12 months and who underwent at least one VUD. We excluded the women with known anatomic abnormalities of the urinary tract such as urethra stricture and vesicoureteral reflux, women who received immunosuppressive treatment, pregnant women, and those with nonbacterial urinary tract infection, from the study. The diagnosis of UTI was made in the women, who had clinical signs such as dysuria, leukocyturia, and bacteriuria ( $\geq 10^{5}$ colonies $/ \mathrm{mL}$ ).

The evaluated data were prospectively collated and included: women demographics (age) and lower urinary tract symptoms (LUTS) such as voiding frequency, nocturia episodes, and irrepressible urgency. We also assessed the urine culture results and the instigated treatment after VUD. The UTIs were diagnosed via urine sediment and culture. All women were evaluated via complete history, voiding diary, physical investigation, sonography, and VUD. The study was approved by the Ethics Committee of the University Medical Center Goettingen (permit 5/4/15). Informed consent from individual participants was not required for this type of study.

All VUDs were performed by an expert urogynecologist using a standardized practice in accordance to the recommendations of the International Continence Society (ICS). ${ }^{9}$ We performed VUD to measure cystometric variables and to detect voiding disorders. The following variables were measured during the VUD: cystometric bladder capacity, maximum flow rate $\left(\mathrm{Q}_{\max }\right)$, post-void residual (PVR) volume, detrusor pressure at $\mathrm{Q}_{\max }\left(\mathrm{P}_{\text {det }}\right)$, and external urethral sphincter electromyography. Definitions of urodynamic disorders were also made using the recommendations of ICS. ${ }^{9}$

After processing the VUD, the women were followed up routinely at 3, 6, and 12 months by the same urogynecologist. The women in these practices were asked at each post-VUD visit about LUTS, voiding frequency, nocturia, and urgency. At follow-up visits, women were assessed via urinalysis and microbiological investigations.

\section{Statistics}

The data were analyzed using the Statistical Package for the Social Sciences (SPSS, Inc., Chicago, IL, USA) program. We used a Student's $t$-test for continuous data and chi square test for dichotomous data. The significance level was set at a $P$-value of less than 0.05 .

\section{Results}

The median age of the women was $65 \pm 19$ years ( $20-83$ years). Neurogenic and non-neurogenic voiding dysfunctions were found in 4\% (two of 54) and 63\% (34 of 54) of women respectively. Reduction in the maximal urinary flow rate to less than $15 \mathrm{~mL} / \mathrm{s}$ and PVR were identified in 63\% (34 of 54 ) and $54 \%$ (29 of 54) of women respectively. The LUTS are described in Table 1.

Using VUD, detrusorsphincterdyssynergia (DSD) and DU were found in $17 \%$ (nine of 54) and 22\% (12 of 54) of women, respectively. A combination of DSD and DU was diagnosed in $11 \%$ (six of 54 ) of women. The OAB syndrome was determined in $28 \%$ (15 of 54) of women. Stress urinary incontinence was noticed in 39\% (21 of 54) of women with a median pad usage of three pads (range: 1-15) daily. Cystometric parameters are described in Table 2.

In the study, Escherichia coli was responsible for $53 \%$ of the recurrent infection episodes. After VUDs, 41\% (22 of 54) of women received antibiotic prophylaxis with nitrofurantoin or co-trimoxazole.

Based of urodynamic findings, $13 \%$ (seven of 54) of women with $\mathrm{OAB}$ received pharmacological treatment with antimuscarinic and two women with refractory $\mathrm{OAB}$ were treated with intravesicular botulinum toxin A injection. One woman with local estrogen vaginal atrophy was treated with local estrogen. We treated 20\% (11 of 45) of women suffering from recurrent UTIs and DU with cholinergics. All women with DSD received a combination treatment with biofeedback and tamsulosin. Four women with moderate and severe stress urinary incontinence were treated with tension-free vaginal tape placement.

\section{Discussion}

Recurrent UTIs are a known distress in women, which represent a challenge for their health care professionals. Although several groups try to explain the possible different pathophysiologic mechanisms of recurrent UTIs, the final mechanism is still not well understood. ${ }^{1,4,5}$ Recurrent UTIs are thought to result from a variety of factors,

Table I Lower urinary tract symptoms (LUTS)

\begin{tabular}{ll}
\hline & Study group $(\mathbf{n = 5 4})$ \\
\hline Voiding frequency (median \pm SD [range]) & $7 \pm 4(I-13)$ \\
Nocturia $>2(\mathrm{n}[\%])$ & $23(43 \%)$ \\
Nocturia (median \pm SD [range]) & $1 \pm 3(0-12)$ \\
Urgency $(\mathrm{n}[\%])$ & $29(54)$ \\
\hline
\end{tabular}

Abbreviation: SD, standard deviation. 
Table 2 Cystometric parameters

\begin{tabular}{ll}
\hline & Study group $(\mathbf{n}=\mathbf{5 4})$ \\
\hline$C B C(\mathrm{~mL})($ median $\pm \mathrm{SD}$ [range]) & $356 \pm 208(30-950)$ \\
$\mathrm{Q}_{\max }(\mathrm{mL} / \mathrm{s})($ median $\pm \mathrm{SD}[$ range] $)$ & $12 \pm 9(2-46)$ \\
$\mathrm{Q}_{\max }\left(\mathrm{P}_{\operatorname{det}}\right)\left(\mathrm{cmH}_{2} \mathrm{O}\right)($ median $\pm \mathrm{SD}[$ range] $)$ & $35 \pm 21(5-124)$ \\
\hline
\end{tabular}

Abbreviations: $C B C$, cystometric bladder capacity; $S D$, standard deviation; $Q_{\text {max' }}$, maximum flow rate; $Q_{\text {max }}\left(P_{\text {det }}\right)$, detrusor pressure at $Q_{\text {max }}$.

including urinary tract malformations, increasing usage of antimicrobial agents, and voiding dysfunctions. ${ }^{10}$ Bladder dysfunction and significant LUTS lead to proliferation of microorganisms. Bacterial persistence in quiescent intracellular reservoirs, despite treatment of the infection, can remain in underlying or superficial bladder epithelial tissue and are capable of causing recurrent UTIs..$^{4,11,12}$ Although the vast majority of women with recurrent UTIs have a normal voiding function, urodynamic disorders may be an important factor associated with recurrent UTI risk. The voiding dysfunction may manifest in urgency, frequency, and urinary incontinence. ${ }^{13}$ In the case of urinary incontinence, bacteria growing around the meatus can be introduced into the urethra to manifest a UTI.

Recent groups discuss the role of urodynamic disorders that can predispose to recurrent UTIs. ${ }^{5,10} \mathrm{~A}$ further group has shown that recurrent UTIs can be associated with several functional disorders of LUTS detected by VUD, predisposing women to recurrent UTIs, including DU, DSD, and OAB.${ }^{13}$ In our study, we found changes in video-urodynamic investigations for $67 \%$ of women suffering UTIs. The most common urodynamic disorder was DU. The DU leads to impaired bladder emptying, reduced urinary flow rate, and raised PVR volume. Urodynamically, we found a reduced voiding pressure with the failure of the bladder to empty efficiently in the women with DU. Rudaitis et al has shown that abnormal voiding frequency and residual urine are independent risk factors for recurrent UTIs in girls. ${ }^{10}$ On the other hand, he indicated that none of the urodynamic factors was significantly associated with recurrent UTIs. Mazzola et al reported that the most frequent isolated voiding abnormalities in younger women with recurrent UTIs were infrequent voiding, dysfunctional voiding, and poor fluid intake. ${ }^{13}$ The permanent LUTS during infection free episodes were noted in $52 \%$ of women with recurrent UTIs in our study. The LUTS can be caused by OAB or permanent residual urine due to DU, DSD or the combination of both.

Therefore, the correct knowledge of the microbiological characteristics is of paramount importance for an adequate management of recurrent UTIs. The analysis of antimicrobial investigations found $E$. coli to be the most diagnosed bacterium in our study. The binding to the urothelial surface of uropathogenic $E$. coli increases their ability to colonize and persist in the urogenital tract. ${ }^{14}$ The E. coli is the most common organism causing UTIs, responsible for approximately $85 \%$ of UTIs. ${ }^{14,15}$

The VUD is the most specific investigation in the diagnosis of lower urinary tract function. The diagnosis and treatment of lower urinary tract dysfunctions in the women with recurrent UTIs is very important to decrease the infection episodes. The micturition disturbances and functional dysfunctions of the lower urinary tract coexist with recurrent UTIs. Based on the urodynamic results of the study, we believe that recurrent UTIs may not be the cause but the consequence of functional disorders of bladder and/or urethra. In turn, inflammation of the bladder wall can support a dysfunction of the lower urinary tract.

There are a few limitations to our study. The number of enrolled patients in the study was small $(n=54)$. Our study is further limited by its retrospective nature and the lack of a control group.

\section{Conclusion}

Recurrent UTIs may be encouraged by functional disorders of the lower urinary tract. Video-urodynamic evaluation would offer valuable information to confirm the diagnosis of voiding dysfunction in the women suffering from recurrent UTIs.

\section{Author contributions}

Sameh Hijazi contributed conception and design. Sameh Hijazi and Conrad Leitsmann contributed acquisition of data and analysis. All authors contributed toward data analysis, drafting and critically revising the paper, and have read and approved the final version and agree to be accountable for all aspects of the work.

\section{Disclosure}

Sameh Hijazi gave a scientific lecture in public education for Allergan. The authors report no other conflicts of interest in this work.

\section{References}

1. Foxman B. Epidemiology of urinary tract infections: incidence, morbidity, and economic costs. Am J Med. 2002;113(Suppl 1A):5S-13S.

2. Carlson KJ, Mulley AG. Management of acute dysuria. A decision-analysis model of alternative strategies. Ann Intern Med. 1985;102(2): 244-249

3. Engel JD, Schaeffer AJ. Evaluation of and antimicrobial therapy for recurrent urinary tract infections in women. Urol Clin North Am. 1998; 25(4):685-701, x. 
4. Finer G, Landau D. Pathogenesis of urinary tract infections with normal female anatomy. Lancet Infect Dis. 2004;4:631-635.

5. Carlson KV, Rome S, Nitti VW. Dysfunctional voiding in women. J Urol. 2001;165:143-148.

6. Groutz A, Blaivas JG. Non-neurogenic female voiding dysfunction. Curr Opin Urol. 2002;12:311-316.

7. Aliaev IuG, Gadzhieva ZK, Rapoport LM, Tsarichenko DG, Kazilov IuB. [Imperative and obstructive urination disorders in patients with chronic inflammatory diseases of the urinary tract]. Urologiia. 2013; 1:7-10:12. Russian.

8. Wagenlehner FM, Bartoletti R, Cek M, et al. Antibiotic stewardship: a call action by the urologic community. Eur Urol. 2013;64(3):358-360.

9. Abrams P, Cardozo L, Fall M, et al; Standardisation Sub-committee of the International Continence Society. The standardisation of terminology of lower urinary tract function: report from the Standardisation Sub-committee of the International Continence Society. Neurourol Urodyn. 2002;21:167-178.
10. Rudaitis S, Pundziene B, Jievaltas M, Uktveris R, Kevelaitis E. Recurrent urinary tract infection in girls: do urodynamic, behavioral and functional abnormalities play a role? J Nephrol. 2009;22:766-773.

11. Mysorekar IU, Hultgren SJ. Mechanisms of uropathogenic Escherichia coli persistence and eradication from the urinary tract. Proc Natl Acad Sci U S A. 2006;103:14170-14175.

12. Foxman B. Urinary Tract Infection in Postmenopausal Women. Curr Infect Dis Rep. 1999;1:367-370.

13. Mazzola BL, von Vigier RO, Marchand S, Tönz M, Bianchetti MG. Behavioral and functional abnormalities linked with recurrent urinary tract infections in girls. J Nephrol. 2003;16:133-138.

14. Svanborg C, Goldaly G. Bacterial virulence in urinary tract infection. Infect Dis Clin North Am. 1997;11:513-529.

15. Lemack GE, Amundsen C, Badlani G, et al. Highlights from the combined Society of Urodynamics and female Urology, and International Society of Pelvic Neuromodulation annual meeting. J Urol. 2007; 177(2):691-695.

\section{Publish your work in this journal}

The International Journal of Women's Health is an international, peerreviewed open-access journal publishing original research, reports, editorials, reviews and commentaries on all aspects of women's healthcare including gynecology, obstetrics, and breast cancer. The manuscript management system is completely online and includes

\section{Dovepress}

a very quick and fair peer-review system, which is all easy to use. Visit http://www.dovepress.com/testimonials.php to read real quotes from published authors. 